\title{
Assessing Low Voltage Network Constraints in Distributed Energy Resources Planning
}

\author{
C. F. Calvillo ${ }^{1 *}$, A. Sánchez-Miralles ${ }^{1}$, J. Villar ${ }^{1}$ \\ ${ }^{1}$ Institute for Research in Technology (IIT) \\ ICAI School of Engineering, Comillas Pontifical University \\ Santa Cruz de Marcenado 26, 28015, Madrid, Spain
}

\author{
* Corresponding author \\ Email addresses: christian.calvillo@iit.upcomillas.es (C.F. Calvillo), \\ alvaro@upcomillas.es (A. Sánchez-Miralles), jose.villar@iit.upcomillas.es (J. Villar)
}

\begin{abstract}
Many efforts are being devoted towards achieving optimal planning and operation of Distributed Energy Resources (DER). However, during the planning process, not all relevant thermal constraints of the distribution network are considered; some works claim that they must be taken into account, while others follow the single-node approach.

This paper assesses the effects of the distribution network thermal constraints in DER planning, using a deterministic linear programming problem to find the optimal DER planning and operation. Three case studies with different network topologies under several DER implementation scenarios are analyzed. A DC load flow is used to estimate the required network reinforcements to accommodate optimal DER investments, if any. Reinforcement costs are then calculated to assess the net benefit compared to limiting DER investments and operation, according to the network thermal limits. Results suggest that there is no significant economic advantage in limiting DER investments and line flows, compared to reinforcing the low voltage network to allow the larger flows that result from an unconstrained network problem.
\end{abstract}

Keywords: Distributed Energy Resources; Renewable Sources; Energy Storage; Distribution Network; Energy System Planning Models.

\section{Introduction}

Energy is one of the most demanding issues in current and future urban centers, especially considering the increasing complexity of its systems and sustainability requirements [1]. In this setting, Distributed Energy Resources (DER) stand as a promising alternative to contribute to sustainability, security of supply, and energy efficiency [2]. DER commonly refers to distributed generation (essentially based on renewable energy sources), but also in addition to distributed energy storage, and demand response strategies as well. 
The benefits and requirements of these decentralized schemes have been widely studied. DER systems are presented in [3] as promising energy solutions, describing how their expected massive deployment would result in important changes in current power systems. In [4] it is pointed out how DER eases the integration of renewable energy and how, by using storage systems, the stability problems related with their intermittency and lack of dispatchability can be lessened.

Two main approaches have been adopted for DER planning: one from the perspective of the distribution system operators, and another from the perspective of retailers acting as aggregators. On the one hand, distribution system operators (DSOs) can better control the total aggregated resources, in theory providing more stability, quality of service [6] and energy efficiency to the grid (minimizing losses and network investments) [5]. This approach normally deals with high-to-medium voltage levels. On the other hand, aggregators can manage many DER owners, also known as prosumers (producerconsumers, [23]), optimizing the operation and planning of their systems in a coordinated way while partaking in the electricity and ancillary services markets [7]. Individual prosumers are not usually big enough to directly participate in the markets due to its entry barriers [8], hence the advantage of aggregating them to profit from wholesale market benefits [9]. In this sense aggregators concentrate more on consumers than on the network, maximizing individual and aggregated benefits, thus deal mainly with medium-to-low voltage levels.

When the DSO approach is applied, many studies focus on the impact of DER planning on the network operation and its expansion. A model planning the expansion of the distribution network considering sizing, placement and timing of DER investments and/or network reinforcements is proposed in reference [8]; in [10], a quantification of the impact of different penetration levels of distributed generation on distribution network costs is presented, analyzing three actual geographical distribution areas. Another relevant example is the Reference Network Model presented in [11] which is a large-scale distribution planning tool used to plan distribution networks from scratch or incrementally from an existing grid. This Reference Network Model is also used in [12] in combination with an algorithm that optimizes the location, size, and supply area of the medium-to-low voltage transformer substations with the objective of minimizing costs.

Unlike the above-mentioned models where the network is of prime importance, DER planning models from the aggregator perspective follow a very different approach. For instance, in [13] it is described as a commercial tool for optimal sizing and operation of DER in microgrids, with many applications in different research projects, such as those described in [9]. There are numerous examples of Electric Vehicle (EV) aggregation, considered an interesting type of DER, given their energy storage capabilities. For instance, a mixed-integer linear programming model is proposed in [4], where an aggregator schedules the charge and discharge of EVs, maximizing the profit of the concerned agents while also taking into account energy markets, customer preferences and battery degradation. Similarly, two business models for aggregating EVs are comprehensively described in [7], including all the relationships between the different stakeholders that take part on the energy system. In this work, the capabilities of the EV as a DER system, and the potential benefits of aggregation are remarked upon. Nevertheless, these works commonly focus on the optimization and management of 
energy consumption, considering individual benefits only, and due to the small size of the applications, paying little attention to their impact on the grid.

For large DER penetration, the aggregator perspective could cause problems to the distribution power system producing bidirectional power flows (most grid protections are not design for such flows), reaching lines' thermal limits and producing instability on the grid [15]. Although this concern has been studied more for the medium voltage level, the effects on the final customers at the low voltage distribution network are starting to attract attention [20].

It is important to note that the joint optimization problem that results from DER planning, combined with its impact on the distribution network and its potential expansion, is complex and has no easy solution. Moreover, despite the amount of related research available, there is no work addressing the mentioned optimization problem as a whole. This paper intends to fill this gap by proposing a joint solution of an aggregator-type optimization problem, while also including distribution network thermal constraints. Although no optimal distribution network expansion is computed, the followed approach detects whether thermal limits are reached and then computes the corresponding network reinforcement cost, assessing the benefits of this reinforcement against limiting the power flows.

This paper proposes a linear programming model for the optimal planning of DER in an urban network or energy district composed of several buildings managed by an aggregator. The effects of the network thermal constraints (power lines' thermal limits) are analyzed, and their significance in the planning stage is discussed. The model accepts different small district network topologies and climatic characteristics (Madrid, in the case examples). Solar photovoltaics (PV) and air-source heat pumps (HP) are used as representative DG technologies for electric and thermal energy production, and conventional battery systems are considered for energy storage. The assessment of the impact of network thermal constraints in the planning and operation of DERs is the main contribution of this paper. It is achieved by comparing the benefit of implementing an optimal DER planning and operation with the corresponding network reinforcements, with the benefit that results from limiting DER investments and operation so that the network thermal limits are not violated.

The rest of the paper is organized as follows. In Section 2, a brief description of the optimization model can be found, while in Section 3 its nomenclature and full mathematical formulation is presented. In Section 4 the three case studies considered in this research and the DER implementation scenarios are described. Results of the case studies and a discussion of their implications are provided in Section 5. Concluding remarks can be found in Section 6.

\section{Model description}

The block diagram of the proposed optimization model can be found in Fig. 1. Inputs include the costs and performance characteristics (e.g., electric efficiency, thermal efficiency, power rating, and losses) of the DER systems considered, energy demands and prices (considered as exogenous variables). Outputs comprise optimal investments planning and operation of DER systems, with the corresponding grid energy buying and selling schedules. The model can include network constraints to limit DER investments 
and operation. When these network constraints are not included, a simplified DC load flow analysis can be computed to detect the lines that should be reinforced not to exceed their thermal limit. An economic analysis can then be performed to compare the benefits of both alternative solutions.

\section{Linear programming problem}

This section describes the optimization model to find the optimal scaling and operation of DER (PV systems, HP systems, batteries, and demand response schemes) to be installed in a set of buildings connected by a distribution network. It is considered that the buildings do not have any preexisting DER installation. This linear programming problem considers a typical year's operation characterized by 12 days, each one representing a month of the year. This year is then replicated for the total length of the study. It is important to remark that the constraints of the linear programming model are the same for all case studies, except when the network thermal constraints are taken into account.

\subsection{Nomenclature}

The general nomenclature of the generation and the storage models and the operation of the energy systems are presented next.

Sets:

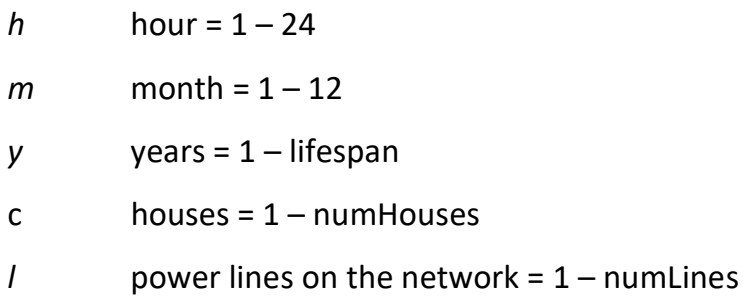

\section{Parameters:}

\begin{tabular}{|c|c|}
\hline lifespan & Expected lifespan for PV and HP systems in the study (years) \\
\hline numHouses & Number of houses (nodes) in the district \\
\hline numLines & Number of power lines in the district \\
\hline demandElec $c, m, h$ & Base electric demand curve for 12 representative days ( $k W h$ ) in each house \\
\hline demandTherm $_{c, m}$ & Total thermal demand for 12 representative days (kWh) \\
\hline hourlyPrice $m, h$ & Normalized electric hourly prices referred to the base price costEy (\%) \\
\hline $\operatorname{cost} E_{y}$ & Electric energy base buying price at year y (USD/kWh) \\
\hline sellE $E_{y}$ & Electric energy base selling price at year y (USD/kWh) \\
\hline $\operatorname{cost} T_{y}$ & Thermal energy base buying price at year $y$ (USD/kWh) \\
\hline fixEpow & access tariff for electric power (USD/kW) \\
\hline fixTpow & access tariff for thermal power (USD/client) \\
\hline$D N I_{m, h}$ & Direct normal irradiance at month $m$, hour $h(\mathrm{~W})$ \\
\hline lossesPV & Total electric losses in the PV system (\%) \\
\hline lossesHP & Total thermal losses in the HP system (\%) \\
\hline costPV & Total cost per installed Watt of PV (USD/W) \\
\hline
\end{tabular}


costHP

costBat

(USD/Wh)

OMfixPV

(USD/W)

OMfixHP

(USD/W)

COP

demandShift

DRequipCost

daysInMonth

effBat

lineCap

\section{Variables:}

powerPV $_{c}$
powerHP
elecEnergylnput $c_{c, m, h}$
gridEnergyBought ${ }_{c, m, h}$
hour $h(\mathrm{kWh})$

boughtEnergy $T_{c, m}$
demand in month $m(\mathrm{kWh})$

ProdPV $_{c, m, h}$

batCapacityc

$S O C_{c, m, h}$

$\operatorname{disBat}_{c, m, h}$

$\operatorname{chBat}_{c, m, h}$

gridEnergySold $c, m, h$

transferredEnergy $y_{c, m, h}$

receivedEnergy $y_{c, m, h}$

decDemand $_{c, m, h}$

(kWh)

incDemand $_{c, m, h}$

(kWh)

demandNew $w_{c, m, h}$

powElect

load $_{c, m, h}$ receivedEnergy) at each house $c$ at month $m$, hour $h(\mathrm{~kW})$.

lineFlow $l, m, h$

Number of days in month $m$

Maximum power line capacity
Total cost per installed Watt of HP (electric power input) (USD/W)

Total upfront cost of batteries, considering a replacement every 8 years

Fixed annual Operation and Maintenance costs per installed Watt of PV

Fixed annual Operation and Maintenance costs per installed Watt of HP Coefficient of Performance for the HP

maximum allowed load to be shifted per day of the base electric demand (\%) costs of equipment required in each house to do load shifting (USD/house)

Battery charge/discharge efficiency ratio (\%)

Installed capacity of PV in house $c(\mathrm{~kW})$

Installed capacity of HP in house $c(k W)$

Electricity for thermal production with HP in house $c$ at month $m$, hour $h(\mathrm{kWh})$

Electricity bought in house $c$ from the grid to meet the demand at month $m$,

Thermal energy bought (natural gas) in house $c$ from the grid to meet the daily

Electric PV production in house $c$ at month $m$, hour $h(\mathrm{kWh})$

Installed capacity of the battery system in house $c(\mathrm{kWh})$

Battery State-of-Charge in house $c$ at month $m$, hour $h(\mathrm{kWh})$

Energy discharged from battery in house $c$ at month $m$, hour $h(\mathrm{kWh})$

Energy charged to the battery in house $c$ at month $m$, hour $h$ (kWh)

Electricity sold in house $c$ to the grid at month $m$, hour $h(\mathrm{kWh})$

Electricity transmitted (surplus) from house $c$ at month $m$, hour $h(\mathrm{kWh})$

Electricity received (shortage) in house $c$ at month $m$, hour $h(\mathrm{kWh})$

Decrease in base demand from demandElec of house $c$ at month $m$, hour $h$ Increase in base demand from demandElec of house $c$ at month $m$, hour $h$ New consumption curve after changing the base profile of demandElec. contracted annual electric power in house $c(k W)$.

Total load (electric demand + transferredEnergy - electric production Total energy flow at each power line $/$ at month $m$, hour $h$ (kWh). 


\subsection{Mathematical formulation}

\section{Objective function}

The proposed objective function maximizes the benefits of all the prosumers (producerconsumers) in the network in an aggregated manner; this is done by reducing the equivalent energy costs and by selling energy back to the grid. Indeed, the objective function is composed by the energy incomes and costs, and the costs of the DER, including both equipment investments and maintenance costs. It is calculated as:

$\max \left\{\begin{array}{l}s e l l_{-} E E-\cos t_{-} E E-\cos t_{-} P V-O M_{-} P V-\cos t_{-} B a t-\cos t_{-} E T-\cos t_{-} P o w T \\ -\cos t_{-} H P-O M_{-} H P-\cos t_{-} D R\end{array}\right\}$

Where:

sell_EE $=\sum_{\mathrm{y}}\left(\operatorname{sellE}_{y} * \sum_{c} \sum_{m}\left(\right.\right.$ daysMonth $_{m} * \sum_{h}\left(\right.$ hourly Price $_{m, h} *$ gridEnergySold $\left.\left.\left._{c, m, h}\right)\right)\right)(2)$

$\cos t_{-} E E=\sum_{\mathrm{y}}\left(\cos t E_{y} * \sum_{c} \sum_{m}\left(\right.\right.$ daysMonth $_{m} * \sum_{h}\left(\right.$ hourly Price $_{m, h} *$ gridEnergyBought $\left.\left.\left._{c, m, h}\right)\right)\right)$

$$
\begin{aligned}
& \cos t_{-} \text {PowE }=\text { lifespan } * \sum_{\mathrm{c}}\left(\text { powElect }_{c} * \text { fixEpow }\right) \\
& \cos t_{-} P V=\sum_{\mathrm{c}}\left(\cos t P V^{*} \text { power } P V_{C}\right) \\
& O M_{-} P V=\sum_{\mathrm{c}}\left(O M f i x P V^{*} \text { powerP } V_{C} * \text { lifespan }\right) \\
& \cos t_{-} B a t=\sum_{\mathrm{c}}\left(\cos t \text { Bat }^{*} \text { batCapacity }_{C}\right) \\
& \cos t_{-} E T=\sum_{\mathrm{y}} \cos t T_{y} * \sum_{c} \sum_{m} \text { daysMonth }_{m} * \text { boughtEnergy } T_{c, m} \\
& \cos t_{-} \text {Pow } T=\text { lifespan } * \text { numHouses } * 12 * \text { fixTpow } \\
& \cos t_{-} H P=\sum_{\mathrm{c}} \cos t H P^{*} \text { power } H P_{C} \\
& O M_{-} H P=\sum_{c}\left(O y M f i x H P * \text { powerHP } P_{C} * \text { lifespan }\right) \\
& \cos t_{-} D R=\text { numHouses } * D \operatorname{Re} \text { quipCost }
\end{aligned}
$$

From the previous equations, it can be seen that (2) (respectively (3)) sum up the electricity sold (respectively bought) to the grid. Equation (4) is used to compute the cost of the contracted electricity power amount and (8), (9) relate to the thermal energy costs and access tariffs, respectively. Equations (5), (7), (10) and (12) describe the demand response equipment costs, whereas equations (6) and (11) compute the total operation and maintenance costs.

This objective function is formulated considering the total lifespan of the project set to 20 years with battery replacements every 8 years [21], and investments, if any, take place at the beginning of the study period. 


\section{Constraints}

\section{Positive constraints:}

gridEnergyBought $_{c, m, h} \geq 0$

gridEnergySold $_{c, m, h} \geq 0$

boughtEnergy $T_{c, m} \geq 0$

receivedEnergy $y_{c, m, h} \geq 0$

transferredEnergy $y_{c, m, h} \geq 0$

elecEnergyInput $_{c, m, h} \geq 0$

$\operatorname{disBat}_{c, m, h} \geq 0$

$\operatorname{chBat}_{c, m, h} \geq 0$

batCapacity $_{c} \geq 0$

$S O C_{c, m, h} \geq 0 \quad \forall h \in[0,24]$

powerP $V_{c} \geq 0$

powerHP $\geq 0$

powerElect $_{c} \geq 0$

incDemand $_{c, m, h} \geq 0$

decDemand $_{c, m, h} \geq 0$

demandNew $_{c, m, h} \geq 0$

State-of-Charge constraints:

The following constraints describe the behavior of the battery storage systems, affecting mainly the state-of-charge (SOC) which is the rate of stored energy with respect to the battery maximum capacity, typically expressed as a percentage (similar to a fuel gauge). These constraints limit the charge to the maximum capacity and the discharge to the current energy level. Current SOC is computed from the previous SOC by adding and subtracting the energy charged and discharged.

$$
\begin{aligned}
& \operatorname{SOC}_{c, m=1, h=0}=0 \\
& \operatorname{SOC}_{c, m, h=0}=\operatorname{SOC}_{c, m-1, h=24} \quad \forall m \in[2,12] \\
& \operatorname{SOC}_{c, m, h=1}=\operatorname{SOC}_{c, m, h=24} \quad \forall m \in[2,11] \\
& \operatorname{SOC}_{c, m, h} \leq \text { batCapacity }_{c} \\
& \operatorname{SOC}_{c, m, h}=\operatorname{SOC}_{c, m, h-1}-\text { disBat }_{c, m, h}+\text { chBat }_{c, m, h} \\
& \text { disBat }_{c, m, h} \leq \text { SOC }_{c, m, h-1} \\
& \text { chBat }_{c, m, h} \leq \text { batCapacity }_{c}-\operatorname{SOC}_{c, m, h-1}
\end{aligned}
$$




\section{Demand Response constraints:}

The following equations model load shifting under a demand response scheme. The maximum amount of load that can be shifted per day is limited by the parameter demandshift, as shown in (38). For the scenarios that do not implement demand response, demandshift $=0$.

$$
\begin{aligned}
& \sum_{h} \text { demandNew }_{c, m, h}=\sum_{h} \text { demandElec }_{c, m, h} \\
& \text { demandNew }_{c, m, h}+\text { decDemand }_{c, m, h}=\text { demandElec }_{c, m, h}+\text { incDemand }_{c, m, h} \\
& \sum_{h} \text { incDemand }_{c, m, h} \leq \text { demandShift }^{*} \sum_{h} \text { demandElec }_{c, m, h}
\end{aligned}
$$

\section{Energy Production constraints:}

In (39), prodPV refers to the electric energy produced by the PV system, where DNI stands for Direct Normal Irradiance $(\mathrm{W} / \mathrm{m} 2)$, which is the energy provided by the sun at a specified location. The powerPV refers to the selected size of the system. Lastly, $G$ is the global irradiation received on a horizontal plane ( $G=1000 \mathrm{~W} / \mathrm{m} 2)$. Similarly, (40) presents the thermal generation equation for an air-source heat pump. It is important to remark that thermal generation is considered to have a greater output than its actual production as it is compared with the cost of producing the same amount of energy with a conventional gas boiler at $80 \%$ efficiency.

$$
\begin{aligned}
& \operatorname{prodPV} V_{c, m, h}=\frac{D N I_{m, h} * \operatorname{power} V_{c}}{G} *(1-\operatorname{losses} P V) \\
& \text { boughtEnergy } T_{c, m} \\
& =\text { demandTherm }_{c, m}-\sum_{h}\left(\text { elecEnergyInput }{ }_{c, m, h} * C O P *(1-\text { lossesHP })\right) / 0.8
\end{aligned}
$$

Constraint (41) limits the electric production of the heat pump below the nominal installed power. Continuing with HP operation, (42) applies to the scenarios without demand response schemes, where a flat thermal production (if any) is expected. Conversely, in scenarios with DR, the HP operation can be managed and (43) is intended to avoid thermal generation only in off-peak time, making it produce at least $30 \%$ of total demand in peak hours.

$$
\begin{aligned}
& \text { elecEnergyInput }_{c, m, h} \leq \text { powerHP }_{c} \\
& \text { elecEnergyInput }_{c, m, h}=\text { elecEnergyInput }_{c, m, h-1} \quad \forall h \in[2,24] \\
& \sum_{h}\left(\text { elecEnergyInput }_{c, m, h} * C O P *(1-\text { lossesHP })\right) / 0.8 \\
& \geq 0.3 * \text { demandTherm }_{c, m} \quad \forall h \in[13,20]
\end{aligned}
$$

The following equation is used to calculate the required contracted electric power given the DG production.

$$
\text { powElect }_{c} \geq \text { gridEnergyBought }_{c, m, h}
$$

\section{Balance Equation:}


Equation (45) is required to balance the total energy consumption and production at every period, where all the energy that enters each house is positive and the energy that leaves the house is negative.

$$
\begin{aligned}
& \text { gridEnergyBought }_{c, m, h}-\text { gridEnergySold }_{c, m, h} \\
& =\text { demandNew }_{c, m, h}-\text { prodPV }_{c, m, h}-\text { disBat }_{c, m, h}+\left(\text { chBat }_{c, m, h} / \text { effBat }\right) \\
& + \text { transferredEnergy }_{c, m, h}-\text { receivedEnergy } y_{c, m, h}+\text { elecEnergyInput }_{c, m, h}
\end{aligned}
$$

\section{Energy Interchange:}

Besides electricity buying and selling, the district will have the capability to transfer energy from and to other houses in the same district. (46) describes the behavior of such transfers, considering power line losses.

$\sum_{c}$ receivedEnergy $y_{c, m, h}=$ lineLosses $\sum_{c}$ transferredEnergy $y_{c, m, h}$

\section{Network constraints:}

$$
\begin{aligned}
& \text { load }_{c, m, h}=\text { gridEnergyBought }_{c, m, h}+\text { receivedEnergy }_{c, m, h} \\
& \text {-gridEnergySold }_{c, m, h}-\text { transferredEnergy }_{c, m, h} \\
& \text { lineFlow }_{l, m, h}=\text { load }_{x, m, h}+\text { lineFlow }_{x, m, h} \\
& \text { lineFlow }_{l, m, h} \leq \text { lineCap }
\end{aligned}
$$

The lineFlow constraints refer to the power lines' thermal constraints (maximum power flow allowed in the line (49)). The lineflow calculations for each line vary depending on the network topology, and they are designed as a linear combination of loads and other lineFlows as in a DC load flow analysis. Note that constraints (47) - (49) apply only to those scenarios where network constraints are included within the model.

\section{Scenarios and Case Studies}

Three case studies are developed in this paper. They correspond to three different topologies of urban district networks with different numbers of nodes. Average solar characteristics of Madrid, Spain are considered in all cases, and solar production is calculated with the hourly direct normal irradiance (DNI) data from [16]. The proposed districts consist of standard Spanish households, with average energy use. Table 1 shows the average domestic energy consumption per year in Spain, with the corresponding electrical and thermal shares [17].

Electricity usage curves (taken from [18]) are used to calculate the optimal generation and storage capacity to be installed. Fig. 2a presents the normalized electricity demand curves for a typical day in summer and winter, whereas Fig. $2 b$ shows the monthly evolution of this demand throughout an average year. Note that these demand curves do not include thermal generation, which is considered separately.

A time-of-use electricity tariff with peak and off-peak prices and a flat tariff for thermal energy have been used (Table 2). Note that these tariffs (taken from [19]) include taxes and thus correspond to final Spanish consumers tariffs. The price for selling electricity back to the grid has been set to a flat rate, and a 3\% annual increment has been used for all energy prices. 
Lastly, Table 3 shows the selected generation and storage technologies data used (taken from [1]). The coefficient of performance (COP) of the heat pump is set to 2.5 units.

The demand response schemes presented in this study consider two strategies: the management of the heat pump production, and the shifting of electric load. The DemandShift parameter is estimated considering the appliances that can be more easily shifted in time, such as washing machines, dryers and dishwashers which, according to [17], represent $13.3 \%$ of the total electric consumption of a typical Spanish household. Hence, demandShift parameter has been set to $13 \%$ of total daily load. A cost DRequipCost of 300 USD/house represents the cost of the control devices needed for demand response [22].

Lastly, an economic analysis of the proposed case studies is also provided, considering the value of the objective function as equivalent to the Net Present Value (NPV) of the investment with a discount rate of $3 \%$ per year. This NPV value is formulated from the energy and DER systems costs, and serves to validate the economic feasibility of such systems. The lifespan is set to 20 years for all technologies, except batteries which are expected to be replaced every 8 years [21].

\subsection{Case study A}

This case study includes a small district of 9 households (labeled with numbers), as described in Fig. 3. Table 4 contains the line lengths (labeled with letters) of the network to calculate the cost of the potential network reinforcements. It is important to remark that, in order to solely study the effects of the network thermal constraints given their topologies, all houses in the proposed case studies behave equally, according to the consumption patterns of Fig. 2 and Table 1 . This approach results in a high simultaneity factor, summing up all peaks on the network, which can be considered an unfavorable yet interesting scenario to analyze. Finally, the base load in all the nodes in this study is dimensioned to meet the maximum power peak for the network thermal limits.

According to [10], the typical thermal capacity for the low voltage distribution electric lines in Spain ranges from $100 \mathrm{~A}-415 \mathrm{~A}$ at 400V. Moreover, the approximate cost of building such power lines is $16000 \mathrm{USD} / \mathrm{km}$ [10]. For this study, the maximum power flow is limited to $30 \mathrm{kWh}(\approx 136 \mathrm{~A}$ at $220 \mathrm{~V})$ for all power lines, and the costs of reinforcements of a power line have been considered to be half of the original cost of a completely new power line.

\subsection{Case study B}

Case study B comprises a bigger district with 16 houses, so the effect of a more complex network containing more nodes can be analyzed. It differs from the previous network in the organization of houses. In Case study A, 33.3\% of the houses are on one of the main branches (line $\boldsymbol{C}$ ) and $66.7 \%$ on the other (line $I$ ), whereas the proportion for case $B$ is $56.2 \%$ (line $I$ ) $-44.8 \%$ (line $P$ ).

The organization of the district is described in Fig. 4, while Table 5 presents the lengths of network lines. 


\subsection{Case study C}

Unlike previous cases that contain 2 main branches with different number of houses, this case study has a network with 4 main-branches and equally distributed nodes (4 houses each branch). The objective is to understand the effects of the structure of the network in the optimization problem results. Fig. 5 illustrates the network topology for this case, and Table 6 lists the line lengths.

\subsection{Scenario description}

The combination of different DER systems with the inclusion or not of network thermal constraints has been used to design 5 scenarios, summarized in Table 7. The first scenario serves as a reference to evaluate the impact of DER systems and network constraints. This scenario follows the approach "business as usual" where no DER is implemented. Scenarios 2 and 3 include distributed generation and storage systems (PV, HP and Battery systems), but they do not implement demand response neither in the form of load shifting nor in the management of the heat pump production. Hence, the thermal demand under these scenarios is assumed flat along the day. Finally, scenarios 4 and 5 also include demand response schemes, providing more flexibility in the studied networks. For the sake of clarity, the scenarios are labeled with $D, R$, and $N$ referring to distributed generation, demand response and network constraints, respectively. The uppercase letter indicates the presence of such system on the model, whereas the lower case letter means that the characteristic is not implemented.

\section{Results and discussion}

\subsection{Case study A}

The common practice while designing low voltage distribution networks is to oversize the power lines for the sake of security. However, it can be assumed that the population increase is accompanied with a demand increase in the end-user nodes. Hence, networks with saturated power lines are likely to appear. In order to have a network operation reaching its thermal limits, the energy consumption per node is considered to be equal to 5 houses with the characteristics mentioned in Table 1 and Fig. 2 .

For the first scenario, labeled $\boldsymbol{S}_{d, r, n}$, neither DER systems nor network thermal constraints are included in the optimization model. A post-optimization load flow shows, see Fig. 6 , that line $I$ reaches the maximum capacity for a short period of time on December. Despite this short and small violation on power limits, it can be considered that these loads "fit" in the network. It is important to remark that line losses are not considered in the load flow analysis and, as all houses have equal energy usage, several lines present similar behavior, overlapping in the figure.

The installed PV generation power for all scenarios is listed in Table 8, while the airsource heat pump maximum input power can be found in Table 9. From these tables, it can be seen that in those scenarios without network constraints, the optimal amount of generation power is equal for all houses, as it solely depends on the demand characteristics of the client. On the contrary, line capacity constraints modify the installed power when the flexibility of demand response schemes are not available, as in Scenario $S_{D, r, N}$. Note that the difference is greater regarding heat pump power. The houses located in the more saturated branch produce less thermal energy with the heat 
pump in order to reduce the electricity requirements. Conversely, network thermal constraints are not relevant when all DER are available, as the installed capacity for Scenarios $S_{D, R, n}$ and $S_{D, R, N}$ is the same. This can be attributed to the very small violation (around $3 \%$ ) of line capacity occurred in $S_{D, R, n}$ (see Fig. $7 c$ ) that does not affect significantly the operation of DER and, consequently, the capacity planning.

Regarding storage systems, current batteries prices make them unattractive in most scenarios, as shown in Table 10. It is important to remark that Scenarios $\boldsymbol{S}_{D, r, n}$ and $\boldsymbol{S}_{D, r, N}$ are the only ones implementing storage capacity, due to the network thermal constraints and the lack of flexibility of DG. When the demand response capability is added, as in $S_{D, R, n}$ and $S_{D, R, N}$, the battery systems are no longer implemented, given its relatively high cost.

Table 11 summarizes the contracted power. In comparison to the base case, the scenarios including DG increased their contracted electric power while reducing the thermal power. This is caused by the new electric demand of the heat pump. On the other hand, the electric power did not change significantly in the scenarios with demand response schemes; but the contracted thermal power is reduced considerably.

Regarding to the operation of the network, Fig. 7 illustrates the load flow study under the different DER system scenarios for the winter's peak day. Scenario $\boldsymbol{S}_{D, r, n}$ includes distributed generation and storage but no network constraints (Fig. 7a). Consequently thermal violations take place and line $I$ should be reinforced around $33 \%$ of its original capacity (i.e. to $40 \mathrm{kWh}$ ) to avoid them.

Scenario $S_{D, r, N}$ also includes distributed generation but, unlike the previous scenario, network thermal constraints are included on the linear programming model. Hence, the operation and planning of the distributed resources is optimized but without violating the maximum capacity of the power lines, as shown in Fig. 7b.

The next Scenario, $S_{D, R, n}$, is similar to Scenario $S_{D, r, n}$, with the added capabilities of demand response. From Fig. 7c, it can be noted that violation of line I capacity is much smaller and constant (to avoid the extra cost of higher contracted power) than in Scenario $S_{D, r, n}$. Indeed, demand response (thermal production and a percentage of the daily electricity load) reduces the total amount of energy bought at peak hours and the total contracted power.

Lastly, Scenario $S_{D, R, N}$ includes into the optimization model all DER systems and network thermal constraints. In comparison to Scenario $S_{D, r, N}$, the behavior of power flows in the network is slightly more complex due to the demand response mechanisms, yet it also lays within the thermal limits of the power lines.

To evaluate the importance of considering network constraints in the optimization model the reinforcement costs for each scenario needs to be computed. The following equation is used.

reinf orcementCost $=$ line Reinf_Cost $* \sum_{l} \lambda_{l} *$ lineLength

As mentioned in section 4.1, the cost considered for the reinforcement of the power lines is $8 \mathrm{USD} / \mathrm{m}$ [10]. Line lengths are in Table 4, and $\lambda_{l}$ is the integer coefficient of how 
many times the power line should be reinforced, computed from the violation of its thermal limit under the analyzed scenarios. For instance, for both Scenarios $S_{D, r, n}$ and $S_{D, R, n}, \lambda=\{0,0,0,0,0,0,0,0,1\}$.

The global benefits of the different solutions analyzed are summarized in the objective function values presented in Table 12. Comparing to the base Scenario $\boldsymbol{S}_{d, r, n}$, the inclusion of distributed generation provides savings of $9.44 \%$ when the network constraints are not taken into account with around $0.2 \%$ of increased cost for reinforcements. In contrast savings of $9.16 \%$ are achieved when the network is considered in the optimization model. These small differences suggest that it may be better to just reinforce the lines than the added complexity and additional costs of installing communications systems to measure and control the real-time network status and equipment to manage the DG accordingly.

Regarding the scenarios that also includes demand response, the benefit increases to $17.13 \%$ with a similar reinforcement cost of around $0.2 \%$. The scenario considering network thermal constraints gives almost the same benefits than in $S_{D, R, n}$ without the reinforcement costs. It is important to note that the obtained results for $S_{D, r, N}$ and $S_{D, R, N}$ are very likely to be overvalued, as the real implementation of such coordinated control of network and RES systems could represent considerable costs, reducing the expected benefits.

\subsection{Case study B}

In the second case study more power lines are included, for a total of 16 . Similar to Case study $A$, the load for each node is established to be equal to 5 houses.

The total installed distributed generation of PV, HP and storage systems is listed in Table 13. Similar to Case study $A$, the installed capacity in scenarios without network constraints depends solely on the energy requirements of the house; while in $S_{D, r, N}$, the location of the house within the network affects that decision, being the houses in more saturated lines the ones with a slightly higher capacity installed. It is important to remark that for this case study, battery storage investments were only profitable in Scenarios $S_{D, r, n}$ and $S_{D, r, N}$.

For the comparison between scenarios, the resulting objective function values are summarized in Table 14. The load flow analysis for Scenario $S_{D, r, n}$, (which considers distributed generation) shows that the network requires the reinforcement of lines $\boldsymbol{H}, \boldsymbol{I}$ and $\boldsymbol{P}$. In Scenario $\boldsymbol{S}_{D, R, n}$ which includes DER systems but no network constraints, the behavior is similar to the one in the previous case study. With the added capability of demand response, the network topology and the behavior of loads result in smaller violations in the maximum thermal capacity of power lines. Hence, only lines $\boldsymbol{I}$ and $\boldsymbol{P}$ need to be reinforced to cope with this operation. Similar to the previous case study, the network reinforcement cost is computed for Scenarios $S_{D, r, n}$ and $S_{D, R, n}$, with $\lambda=$ $\{0,0,0,0,0,0,0,1,1,0,0,0,0,0,0,1\}$ and $\lambda=\{0,0,0,0,0,0,0,0,1,0,0,0,0,0,0,1\}$, respectively.

The results in these scenarios are very similar to those of Case study $A$. For the scenario including distributed generation, a 9.44\% savings is achieved with a decrease of approximately $0.1 \%$ in the benefits if the reinforcement costs are considered. For the same system but including network thermal constraints, the total savings are $9.13 \%$. On the other hand, Scenario $S_{D, R, n}$ with all DER available gives $17.13 \%$ savings, and an added 
cost of $0.07 \%$ for network reinforcements; meanwhile, $S_{D, R, N}$ provides a total benefit of $17.12 \%$, which is quite similar to the benefits of Scenario $S_{D, R, n}$. Once more, it can be noted that the difference between considering or not considering the network thermal constraints is not significant. In addition, the benefits of Scenario $S_{D, R, N}$ would decrease if coordinated control costs were taken into account.

\subsection{Case study C}

Lastly, Case study C presents a different organization to see the effects of DER in a network with more main branches and is more balanced. In this case, each node of the district includes the energy consumption patterns of 7.5 houses. The load flow analysis for the scenarios of Case study $C$ shows that many power lines in this network have similar energy flows. For Scenarios $\boldsymbol{S}_{D, r, n}$ and $\boldsymbol{S}_{D, R, n}$, power lines $\boldsymbol{D}, \boldsymbol{H}, \boldsymbol{L}$ and $\boldsymbol{P}$ need to be reinforced. In comparison to Case study $B$, with an equal number of nodes, more power line flows overlap because of the more uniform distribution of houses in the network.

For this case study, planning of DER systems continues with the same trend of previous cases, where slight differences appear in contracted power and in PV and Battery installed capacity only in Scenario $S_{D, r, N}$ (see Table 15). However, the results in HP power show a noticeable change from previous cases, as all nodes of the network implement the same installed capacity. This result can be attributed to the more balanced network proposed in this case study.

The final values of the objective function are another change from previous case studies. Table 16 shows that the percentage of benefits has increased in comparison to previous cases. This can be attributed to the higher number of stressed power lines and the more balanced network.

\subsection{Final summary}

Lastly, for the sake of comparison, the total benefits for all case studies are listed in Table 17. The reviewed networks included 9 and 16 nodes for Case studies $A$ and B, respectively, whereas Case study $C$ also presents a 16-node network, but organized in 4 more balanced branches. From the table below, it is demonstrated that the size of the network is not relevant when the topology is similar, as in Cases A and B. In contrast, Case study $C$ presents a different topology, achieving around $3 \%$ more benefits with respect to the base scenario without DER. This extra profit suggests that, with more saturated lines, more benefits can be obtained from DER systems.

\section{Conclusions}

Three case studies were analyzed, each one proposing a different low-voltage district network. From the results obtained, it can be seen that the size of the network does not significantly affect the percentage of expected benefits of DER systems when the structure of the network is similar. Indeed, from this study, it can be concluded that the household benefits of Distributed Energy Resources (DER) systems can be around 10\% when no demand response is implemented, and near $20 \%$ when it is. In addition, the analysis also suggests that the network structure has an impact on the share of profits. For instance, the network with a higher number of saturated power lines showed around $3 \%$ more benefits from DER systems than the others. 
In the case studies analyzed, it is evident that, by including network thermal constraints in the optimization model, the violation of the limits of the power lines can be avoided while still taking advantage of DER systems with a slight decrease of the expected benefits. However, the comparison of this reduction on the total benefits to the extra costs of introducing network reinforcements where needed (considering only the low voltage network), shows that the difference between them is not significant, suggesting that line reinforcements are a better solution than including network constraints. Certainly, the real implementation of a district capable of operating the energy resources reviewed in this paper with each given network status would require complex communication and control systems as well as additional costs. Therefore, the approach of not considering network constraints can simplify the planning and operation of the systems, boosting the integration of distributed energy resources.

\section{Acknowledgment}

The work of C. F. Calvillo was supported through an Erasmus Mundus Ph.D. Fellowship. The authors would like to express their gratitude to all partner institutions within the Erasmus Mundus Joint Doctorate Program in Sustainable Energy Technologies and Strategies (SETS) as well as to the European Commission for their support.

\section{References}

[1] C. F. Calvillo, A. Sanchez, and J. Villar, "Distributed energy generation in smart cities," in 2013 International Conference on Renewable Energy Research and Applications (ICRERA), pp. 161-166, Madrid, Spain, 20-23 Oct. 2013.

[2] C. F. Calvillo, A. Sánchez, and J. Villar, "Evaluation and optimal scaling of distributed generation systems in a smart city," in 8th International Conference on Urban Regeneration and Sustainability, pp. 845-857, Putrajaya, Malaysia, 35 Dec. 2013.

[3] R. Cossent, T. Gómez, and P. Frías, "Towards a Future with Large Penetration of Distributed Generation: Is the Current Regulation of Electricity Distribution Ready? Regulatory Recommendations Under a European Perspective," Energy Policy 37, no. 3 (March 2009): 1145-1155. doi:10.1016/j.enpol.2008.11.011.

[4] I. J. Fernández, C. F. Calvillo, A. Sánchez-Miralles, and J. Boal, "Capacity fade and aging models for electric batteries and optimal charging strategy for electric vehicles," Energy, vol. 60, pp. 35-43, Oct. 2013.

[5] A. Soroudi, and M. Ehsan, "A Distribution Network Expansion Planning Model Considering Distributed Generation Options and Techo-economical Issues," Energy 35, no. 8 (August 2010): 3364-3374. doi:10.1016/j.energy.2010.04.022.

[6] H. Doagou-Mojarrad, G. B. Gharehpetian, H. Rastegar, and J. Olamaei, "Optimal placement and sizing of DG (distributed generation) units in distribution networks by novel hybrid evolutionary algorithm," Energy, vol. 54, pp. 129-138, Jun. 2013.

[7] A. Sanchez-Miralles, T. Gomez San Roman, I. Fernandez, and C. F. Calvillo, "Business Models Towards the Effective Integration of Electric Vehicles in the 
Grid," IEEE Intelligent Transportation Systems Magazine 6, no. 4 (winter 2014): 45-56. doi:10.1109/MITS.2014.2329327.

[8] CNE - Comisión Nacional de Energía (Spanish Energy National Comission), "LEY DEL SECTOR ELÉCTRICO (Legislation of the electric sector)," 5th Ed., 2008. Accessed November 18, 2014. http://www.cne.es/cne/doc/legislacion/NE LSE.pdf

[9] G. Cardoso, M. Stadler, M. C. Bozchalui, R. Sharma, C. Marnay, A. Barbosa-Póvoa, and P. Ferrão, "Optimal investment and scheduling of distributed energy resources with uncertainty in electric vehicle driving schedules," Energy, vol. 64, pp. 17-30, Jan. 2014.

[10]R. Cossent, L. Olmos, T. Gómez, C. Mateo, and P. Frías, "Distribution network costs under different penetration levels of distributed generation," Euro. Trans. Electric Power, vol. 21, no. 6, pp. 1869-1888, Sep. 2011.

[11] C. M. Domingo, T. G. S. Román, A. Sánchez-Miralles, J. P. P. González, and A. C. Martínez, "A Reference Network Model for Large-Scale Distribution Planning With Automatic Street Map Generation," IEEE Transactions on Power Systems, vol. 26, no. 1, pp. 190-197, Feb. 2011.

[12] L. Gonzalez-Sotres, C. Mateo Domingo, A. Sanchez-Miralles, and M. Alvar Miro, "Large-Scale MV/LV Transformer Substation Planning Considering Network Costs and Flexible Area Decomposition," IEEE Transactions on Power Delivery, vol. 28, no. 4, pp. 2245-2253, Oct. 2013.

[13]“DER-CAM | Microgrids,” Berkeley Lab. Accessed November 11, 2013. http://der.lbl.gov/der-cam

[14]F. Giraud, and Z.M. Salameh, "Steady-state Performance of a Grid-connected Rooftop Hybrid Wind-photovoltaic Power System with Battery Storage," IEEE Transactions on Energy Conversion 16, no. 1 (March 2001): 1 -7.

[15]L. Pieltain Fernández, T.G.S. Román, R. Cossent, C.M. Domingo, and P. Frías, "Assessment of the Impact of Plug-in Electric Vehicles on Distribution Networks," IEEE Transactions on Power Systems 26, no. 1 (2011): 206-213. doi:10.1109/TPWRS.2010.2049133.

[16] European Commission - Joint Research Centre, "Photovoltaic Geographical Information System - Interactive Maps," Accessed April 24, 2013. http://re.jrc.ec.europa.eu/pvgis/apps4/pvest.php

[17] IDAE - Instituto para la Diversificación y Ahorro de la Energía (Spanish institute for energy savings and diversification), "Análisis del consumo energético del sector residencial en España: Informe Final (Analysis of energy consumption of the residential sector in Spain: Final Report)," July 2011. Accessed November 11, 2014.

http://www.idae.es/uploads/documentos/documentos Informe SPAHOUSEC ACC f68291a3.pdf

[18] Red Electrica de España (Electric Grid of Spain, Spanish TSO), "Proyecto INDEL Atlas de la demanda eléctrica española (INDEL project -atlas of Spanish electric 
demand)," Accessed June 11, 2014.

http://www.ree.es/sites/default/files/downloadable/atlas indel ree.pdf

[19]Endesa, "Endesa Online," Accessed June 11, 2014. https://www.endesaonline.com/ES/hogares/index.asp

[20]S. Ruiz-Romero, A. Colmenar-Santos, F. Mur-Pérez, A. López-Rey, "Integration of distributed generation in the power distribution network: The need for smart grid control systems, communication and equipment for a smart city - Use cases," Renewable and Sustainable Energy Reviews, Volume 38, October 2014, Pages 223-234, ISSN 1364-0321, http://dx.doi.org/10.1016/j.rser.2014.05.082.

[21] K. Richa, C. W. Babbitt, G. Gaustad, X. Wang, "A future perspective on lithiumion battery waste flows from electric vehicles, Resources, Conservation and Recycling," Volume 83, February 2014, Pages 63-76, ISSN 0921-3449, http://dx.doi.org/10.1016/j.resconrec.2013.11.008.

[22] “How Much Do Smart Meters Cost?” Emeter. Accessed September 16, 2014. http://www.emeter.com/smart-grid-watch/2010/how-much-do-smart-meterscost/

[23]S. Kesting, and F. Bliek, "Chapter 14 - From Consumer to Prosumer: Netherland's PowerMatching City Shows The Way," In Energy Efficiency, edited by Fereidoon P. Sioshansi, 355-73. Boston: Academic Press, 2013. http://www.sciencedirect.com/science/article/pii/B9780123978790000141. 


\section{Figures}

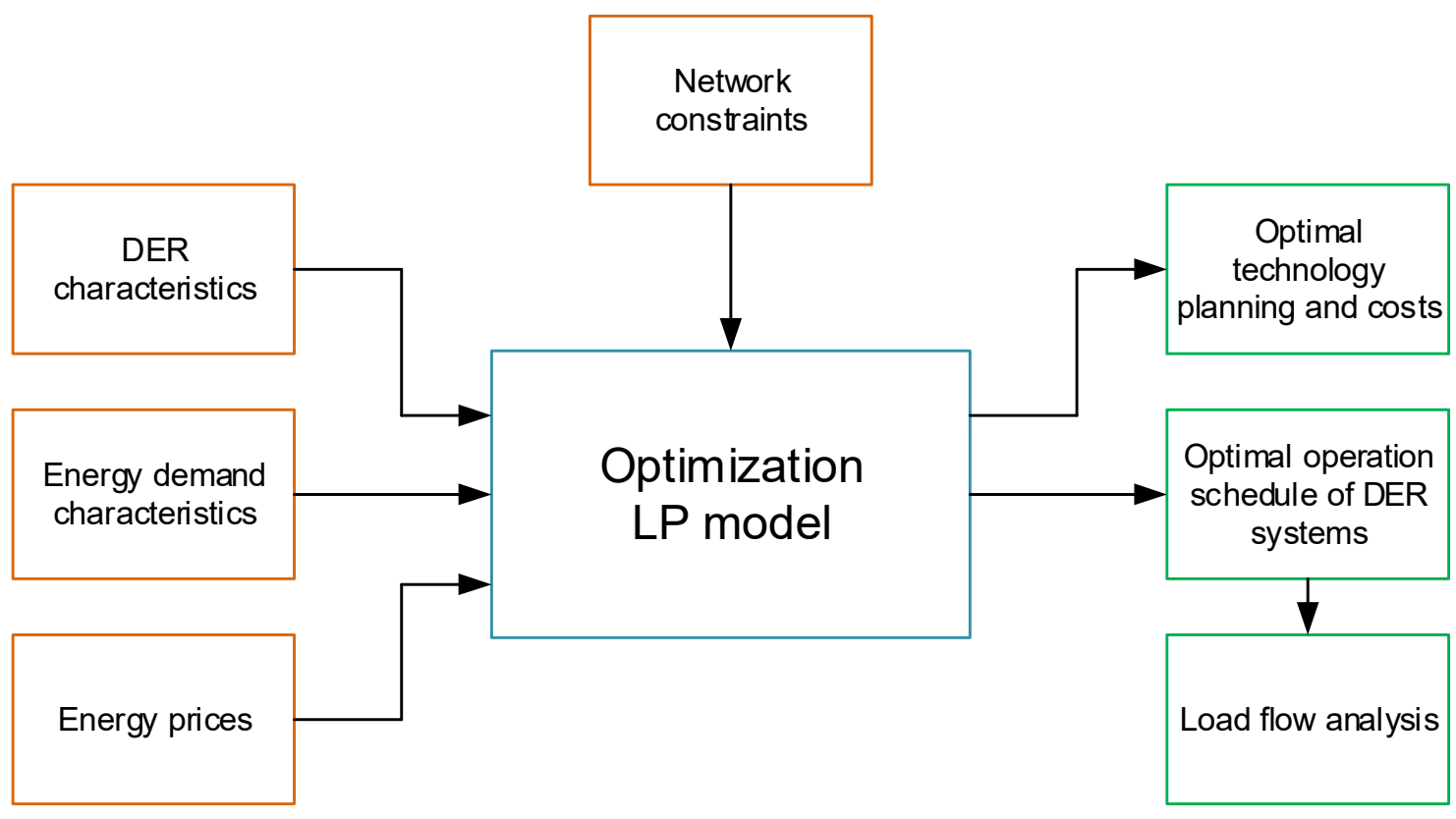

Fig. 1. Block diagram of the proposed optimization model.

a) Typical electric demand curves

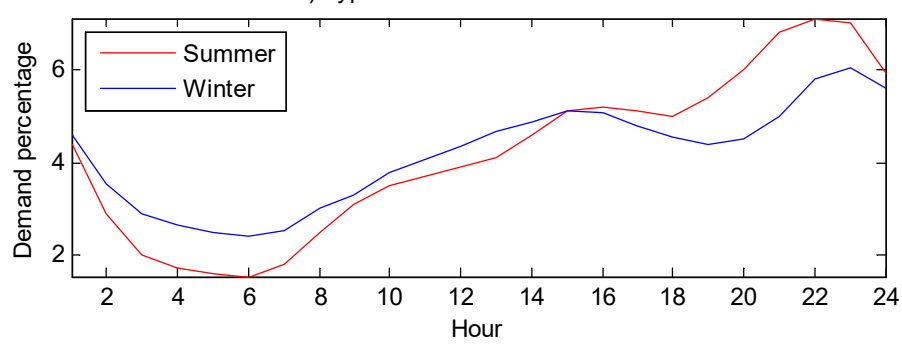

b) Annual demand evolution

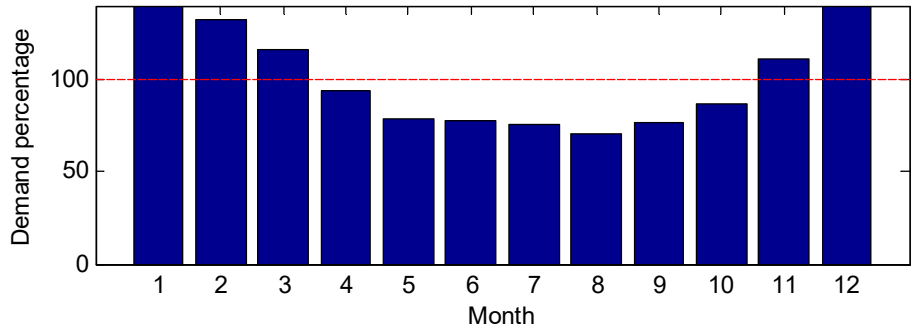

Fig. 2. Demand curves and annual evolution for residential sector in Spain. 


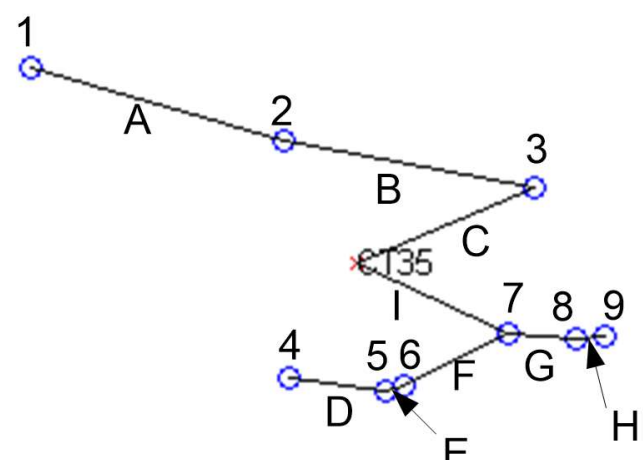

Fig. 3. District electric network: Case study A.

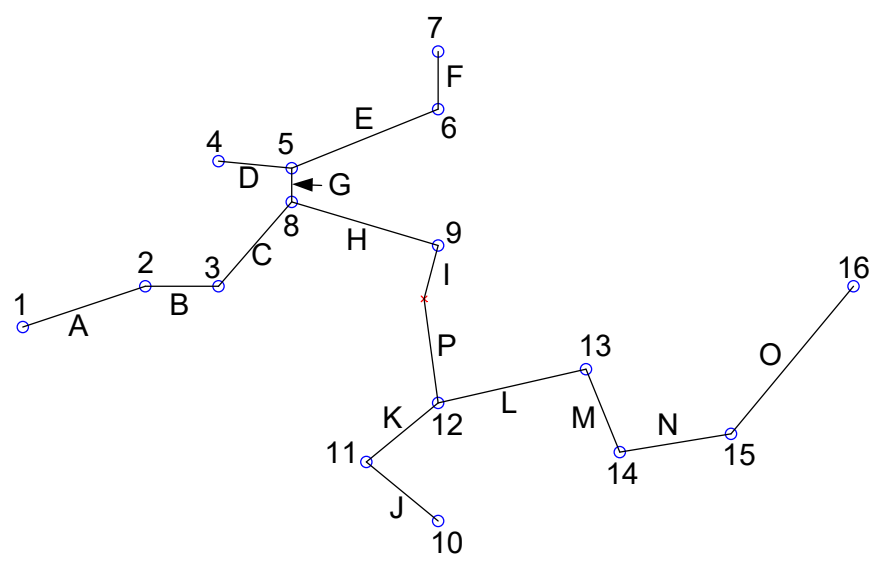

Fig. 4. District electric network: Case study B.

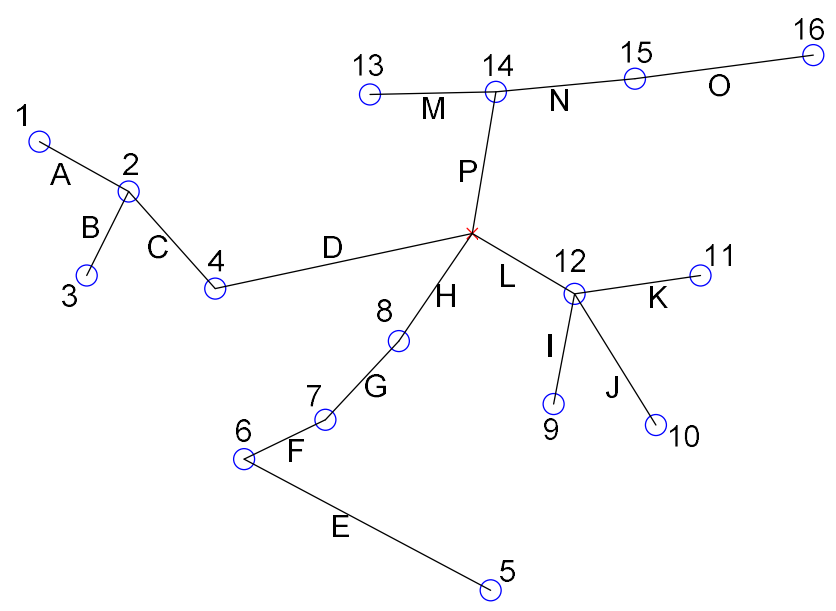

Fig. 5. District electric network: Case study C. 


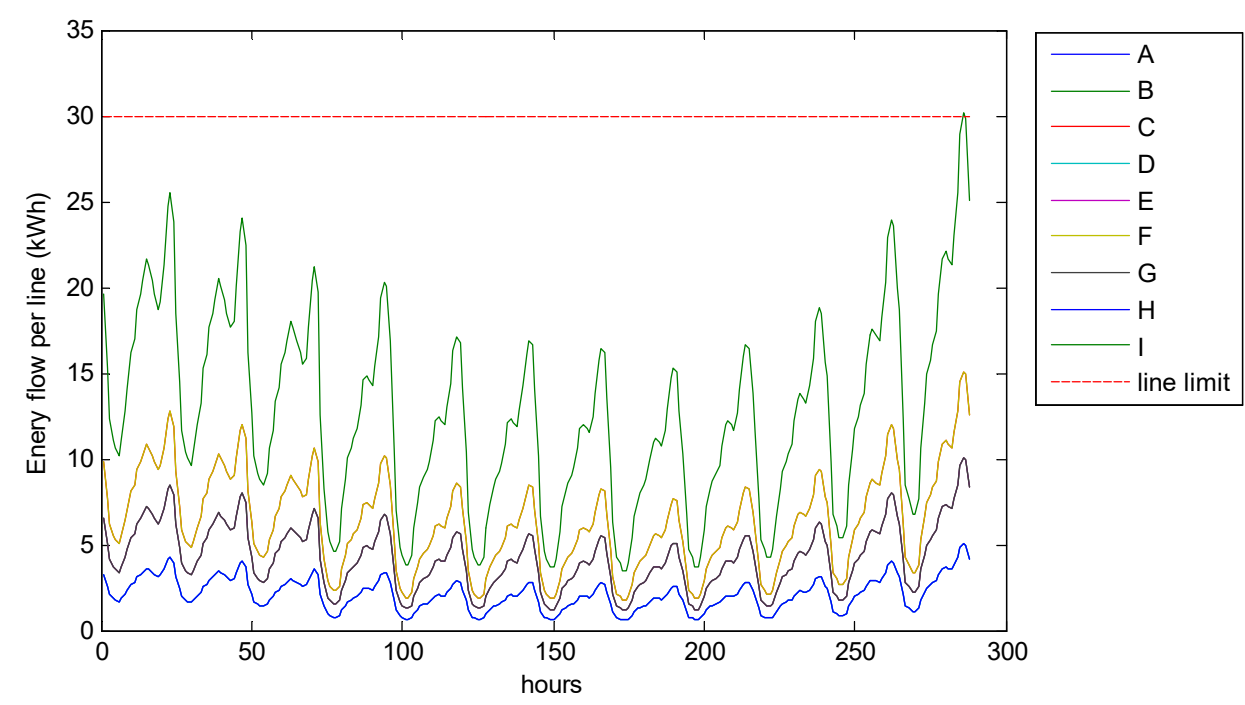

Fig. 6. Power flow analysis for Network $A$ in Scenario $S_{d, r, n}$.
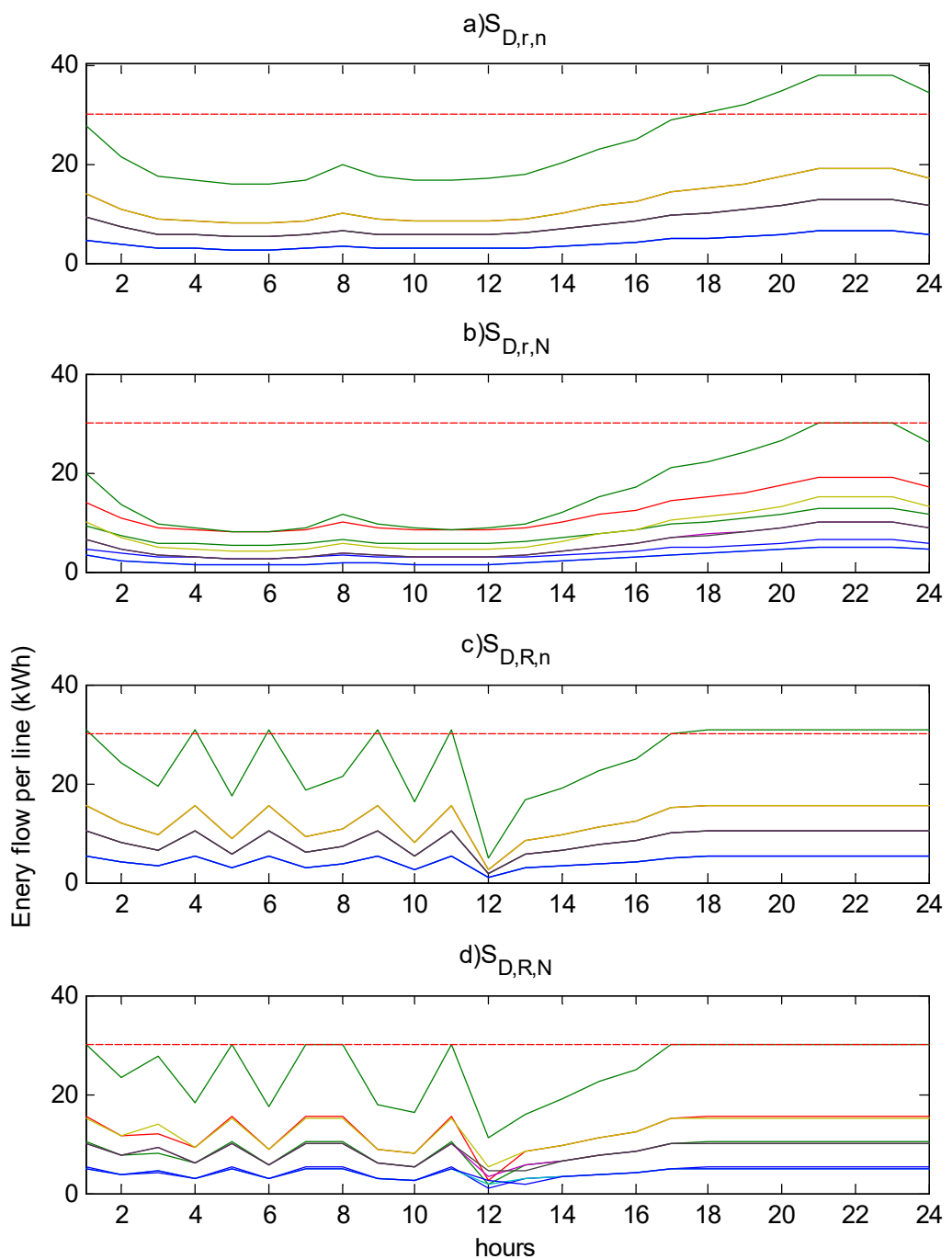

Fig. 7. Load flow analysis detail for a representative day in December (Case study A). 


\section{Tables}

Table 1

Average annual energy consumption per household in Spain (2011).

\begin{tabular}{l|llll}
$\begin{array}{l}\text { Consumption } \\
\text { per Household }\end{array}$ & Electric & $\begin{array}{l}\text { Thermal: } \\
\text { DHW/Heating }\end{array}$ & $\begin{array}{l}\text { Thermal: } \\
\text { Others }\end{array}$ & Total \\
\hline Energy (kWh) & 3698.13 & 6384.85 & 438 & 10.521 \\
Percentage (\%) & $35.15 \%$ & $60.68 \%$ & $4.16 \%$ & $100 \%$
\end{tabular}

Table 2

Tariffs time schedule and pricing.

\begin{tabular}{|c|c|c|}
\hline $\begin{array}{l}\text { Two-price } \\
\text { (electricity): }\end{array}$ & Peak & Off-Peak \\
\hline Winter & $12-22 \mathrm{~h}$ & $23-11 \mathrm{~h}$ \\
\hline Summer & $13-23 h$ & $24-12 h$ \\
\hline Price (USD/kWh) & 0.216 & 0.0734 \\
\hline Access (Annual) & \multicolumn{2}{|c|}{51.94 (USD/kW) } \\
\hline Natural gas tariff: & \multicolumn{2}{|c|}{ Static } \\
\hline $\begin{array}{l}\text { Price (USD/kWh) } \\
\text { Access (Monthly) }\end{array}$ & \multicolumn{2}{|c|}{$\begin{array}{l}0.0743 \\
12.12 \text { (USD/Client) }\end{array}$} \\
\hline Electricity selling tariff: & \multicolumn{2}{|c|}{ Static } \\
\hline Price (USD/kWh) & \multicolumn{2}{|l|}{0.0412} \\
\hline
\end{tabular}

Table 3

Technology costs and expected energy losses.

\begin{tabular}{l|lll} 
Technology & $\begin{array}{l}\text { Inst. } \\
\text { (USD/ W) }\end{array}$ & $\begin{array}{l}\text { Cost } \\
\text { O\&Mfix } \\
\text { (USD/ kW) }\end{array}$ & Losses (\%) \\
\hline PV & 3 & 43 & 24 (electric) \\
HP & 3.1 & 140 & 15 (thermal) \\
Battery & 0.5 (USD/Wh) & - & 10 (electric)
\end{tabular}

Table 4

Line lengths in Case study $A$.

\begin{tabular}{l|lllllllll} 
Line & A & B & C & D & E & F & G & H & I \\
\hline Length $(\mathrm{m})$ & 289.4 & 258.48 & 241.14 & 95.63 & 22.67 & 158.4 & 64.03 & 28.23 & 216.65
\end{tabular}


Table 5

Line lengths in Case study B.

\begin{tabular}{l|llllllll} 
Line & A & B & C & D & E & F & G & H \\
\hline Length $(\mathrm{m})$ & 68.6 & 35 & 79.15 & 35.51 & 86.83 & 50 & 29 & 79.61 \\
& I & J & K & L & M & N & $\mathbf{0}$ & P \\
\hline Length (m) & 46.61 & 61.03 & 61.03 & 76.69 & 71.81 & 56.04 & 139.12 & 89.19
\end{tabular}

Table 6

Line lengths in Case study C.

\begin{tabular}{l|llllllll} 
Line & A & B & C & D & E & F & G & H \\
\hline Length $(\mathrm{m})$ & 40.47 & 42.42 & 55.74 & 98.14 & 109.57 & 35.37 & 45.27 & 57.25 \\
& I & J & K & L & M & N & O & P \\
\hline Length (m) & 68.68 & 46.52 & 52.82 & 47.86 & 67.35 & 51.42 & 46.2 & 66.32
\end{tabular}

Table 7

Scenarios for the optimization model.

\begin{tabular}{l|lll} 
Scenario & $\begin{array}{l}\text { DG } \\
\text { Storage }\end{array}$ & $\begin{array}{l}\text { and } \\
\text { Demand } \\
\text { Response }\end{array}$ & $\begin{array}{l}\text { Network } \\
\text { constraints }\end{array}$ \\
\hline $1, \mathrm{~S}_{\mathrm{d}, \mathrm{r}, \mathrm{n}}$ & $\mathrm{x}$ & $\mathrm{x}$ & $\mathrm{x}$ \\
$2, \mathrm{~S}_{\mathrm{D}, \mathrm{r}, \mathrm{n}}$ & $\checkmark$ & $\mathrm{x}$ & $\mathrm{x}$ \\
$3, \mathrm{~S}_{\mathrm{D}, \mathrm{r}, \mathrm{N}}$ & $\checkmark$ & $\mathrm{x}$ & $\checkmark$ \\
$4, \mathrm{~S}_{\mathrm{D}, \mathrm{R}, \mathrm{n}}$ & $\checkmark$ & $\checkmark$ & $\mathrm{x}$ \\
$5, \mathrm{~S}_{\mathrm{D}, \mathrm{R}, \mathrm{N}}$ & $\checkmark$ & $\checkmark$ & $\checkmark$
\end{tabular}


Table 8

Installed PV power in Case study A (kW).

\begin{tabular}{l|lllll} 
House & $\begin{array}{l}\mathrm{S}_{\mathrm{d}, \mathrm{r}, \mathrm{n}} \\
\text { (base) }\end{array}$ & $\mathrm{S}_{\mathrm{D}, \mathrm{r}, \mathrm{n}}$ & $\mathrm{S}_{\mathrm{D}, \mathrm{r}, \mathrm{N}}$ & $\mathrm{S}_{\mathrm{D}, \mathrm{R}, \mathrm{n}}$ & $\mathrm{S}_{\mathrm{D}, \mathrm{R}, \mathrm{N}}$ \\
\hline $1,2,7,9$ & 0 & 4.059 & 4.059 & 5.346 & 5.346 \\
3 & 0 & 4.059 & 4.011 & 5.346 & 5.346 \\
4 & 0 & 4.059 & 4.087 & 5.346 & 5.346 \\
5,8 & 0 & 4.059 & 4.062 & 5.346 & 5.346 \\
6 & 0 & 4.059 & 4.072 & 5.346 & 5.346 \\
Total: & $\mathbf{0}$ & $\mathbf{3 6 . 5 3 1}$ & $\mathbf{3 6 . 5 3 0}$ & $\mathbf{4 8 . 1 1 4}$ & $\mathbf{4 8 . 1 1 4}$
\end{tabular}

Table 9

Installed heat pump power in Case study A (kW).

\begin{tabular}{l|lllll} 
House & $\begin{array}{l}\mathrm{S}_{\mathrm{d}, \mathrm{r}, \mathrm{n}} \\
\text { (base) }\end{array}$ & $\mathrm{S}_{\mathrm{D}, \mathrm{r}, \mathrm{n}}$ & $\mathrm{S}_{\mathrm{D}, \mathrm{r}, \mathrm{N}}$ & $\mathrm{S}_{\mathrm{D}, \mathrm{R}, \mathrm{n}}$ & $\mathrm{S}_{\mathrm{D}, \mathrm{R}, \mathrm{N}}$ \\
\hline $1-3$ & 0 & 1.502 & 1.502 & 1.803 & 1.803 \\
$4-9$ & 0 & 1.502 & 1.002 & 1.803 & 1.803 \\
Total: & $\mathbf{0}$ & $\mathbf{1 3 . 5 1 8}$ & $\mathbf{1 0 . 5 1 8}$ & $\mathbf{1 6 . 2 2 7}$ & $\mathbf{1 6 . 2 2 7}$
\end{tabular}

Table 10

Installed battery system capacity in Case study A (kWh).

\begin{tabular}{l|lllll} 
House & $\begin{array}{l}\mathrm{S}_{\mathrm{d}, \mathrm{r}, \mathrm{n}} \\
\text { (base) }\end{array}$ & $\mathrm{S}_{\mathrm{D}, \mathrm{r}, \mathrm{n}}$ & $\mathrm{S}_{\mathrm{D}, \mathrm{r}, \mathrm{N}}$ & $\mathrm{S}_{\mathrm{D}, \mathrm{R}, \mathrm{n}}$ & $\mathrm{S}_{\mathrm{D}, \mathrm{R}, \mathrm{N}}$ \\
\hline $1,2,7,9$ & 0 & 0.355 & 0.355 & 0 & 0 \\
3 & 0 & 0.355 & 0.25 & 0 & 0 \\
4 & 0 & 0.355 & 0.416 & 0 & 0 \\
5,8 & 0 & 0.355 & 0.361 & 0 & 0 \\
6 & 0 & 0.355 & 0.384 & 0 & 0 \\
Total: & $\mathbf{0}$ & $\mathbf{3 . 1 9 5}$ & $\mathbf{3 . 1 9 2}$ & $\mathbf{0}$ & $\mathbf{0}$
\end{tabular}


Table 11

Contracted electric/thermal power per node in Case study $A(k W)$.

\begin{tabular}{l|lllll} 
House & $\begin{array}{l}\mathrm{S}_{\mathrm{d}, \mathrm{r}, \mathrm{n}} \\
\text { (base) }\end{array}$ & $\mathrm{S}_{\mathrm{D}, \mathrm{r}, \mathrm{n}}$ & $\mathrm{S}_{\mathrm{D}, \mathrm{r}, \mathrm{N}}$ & $\mathrm{S}_{\mathrm{D}, \mathrm{R}, \mathrm{n}}$ & $\mathrm{S}_{\mathrm{D}, \mathrm{R}, \mathrm{N}}$ \\
\hline 1,2 & $5.03 / 5.32$ & $6.32 / 1.33$ & $6.32 / 1.33$ & $5.12 / 0.53$ & $5.12 / 0.53$ \\
3 & $5.03 / 5.32$ & $6.32 / 1.33$ & $6.37 / 1.33$ & $5.12 / 0.53$ & $5.12 / 0.53$ \\
4 & $5.03 / 5.32$ & $6.32 / 1.33$ & $4.97 / 4.82$ & $5.12 / 0.53$ & $5.01 / 0.53$ \\
$5-9$ & $5.03 / 5.32$ & $6.32 / 1.33$ & $4.99 / 4.82$ & $5.12 / 0.53$ & $5.01 / 0.53$ \\
& & & & & \\
Total: & $\mathbf{4 5 . 2 / 4 7 . 8}$ & $\mathbf{5 6 . 8 / 1 1 . 9}$ & $\mathbf{4 8 . 9 / 3 2 . 9}$ & $\mathbf{4 6 . 8 / 4 . 7}$ & $\mathbf{4 5 . 4 / 3 . 1}$
\end{tabular}

* electric/thermal

Table 12

Objective function values in Case study $A$.

\begin{tabular}{l|lllllll} 
& $\begin{array}{l}S_{d, r, n} \\
\text { (base) }\end{array}$ & $S_{D, r, n}$ & $\begin{array}{l}S_{D, r, n} \\
\text { reinf. }\end{array}$ & $+S_{D, r, N}$ & $S_{D, R, n}$ & $\begin{array}{l}S_{D, R, n} \\
\text { reinf. }\end{array}$ & $+S_{D, R, N}$ \\
\hline $\begin{array}{l}\text { Value } \\
(k €)\end{array}$ & -895.806 & -811.208 & -812.916 & -813.737 & -742.384 & -744.092 & -742.53 \\
Benefit & 0 & $9.44 \%$ & $9.25 \%$ & $9.16 \%$ & $17.13 \%$ & $16.94 \%$ & $17.11 \%$
\end{tabular}

Table 13

Total installed capacity and contracted power in Case study B (kW).

\begin{tabular}{l|lllll} 
& $\begin{array}{l}\text { S } \\
\text { (base) }\end{array}$ & $S_{D, r, n}$ & $S_{D, r, N}$ & $S_{D, R, n}$ & $S_{D, R, N}$ \\
\hline PV & 0 & 64.944 & 64.932 & 85.536 & 85.536 \\
HP & 0 & 24.032 & 18.032 & 28.848 & 28.848 \\
Battery & 0 & 5.68 & 5.655 & 0 & 0 \\
$\begin{array}{l}\text { Contracted } \\
\text { power* }\end{array}$ & $80.4 / 85.1$ & $101.1 / 21.2$ & $85.4 / 67.1$ & $81.9 / 8.4$ & $80.4 / 8.4$
\end{tabular}

* electric/thermal 
Table 14

Objective function values in Case study B.

\begin{tabular}{l|lllllll} 
& $\begin{array}{l}S_{d, r, n} \\
\text { (base) }\end{array}$ & $S_{D, r, n}$ & $\begin{array}{l}S_{D, r, n} \\
\text { reinf. }\end{array}$ & $+S_{D, r, N}$ & $S_{D, R, n}$ & $\begin{array}{l}S_{D, R, n} \\
\text { reinf. }\end{array}$ & $+S_{D, R, N}$ \\
\hline $\begin{array}{l}\text { Value } \\
(k €)\end{array}$ & -1592.55 & -1442.15 & -1443.847 & -1447.21 & -1319.79 & -1320.863 & -1319.95 \\
Benefit & 0 & $9.44 \%$ & $9.34 \%$ & $9.13 \%$ & $17.13 \%$ & $17.06 \%$ & $17.12 \%$
\end{tabular}

Table 15

Total installed capacity and contracted power in Case study C (kW).

\begin{tabular}{l|lllll} 
& Sd,r,n (base) & S $_{D, r, n}$ & $S_{D, r, N}$ & $S_{D, R, n}$ & $S_{D, R, N}$ \\
\hline PV & 0 & 97.408 & 97.6 & 128.304 & 128.304 \\
HP & 0 & 36.048 & 24.032 & 43.264 & 43.264 \\
Battery & 0 & 8.512 & 8.928 & 0 & 0 \\
$\begin{array}{l}\text { Contracted } \\
\text { power* }\end{array}$ & $120.8 / 136.1$ & $151.6 / 31.8$ & $120 / 116.2$ & $122.8 / 12.6$ & $119.8 / 12.6$
\end{tabular}

* electric/thermal

Table 16

Objective Function values in Case study $\mathrm{C}$.

\begin{tabular}{|c|c|c|c|c|c|c|c|}
\hline & $\begin{array}{l}S_{d, r, n} \\
\text { (base) }\end{array}$ & $S_{D, r, n}$ & $\begin{array}{l}\text { SD,r,n }_{\text {reinf. }} \quad+ \\
\text { rein }\end{array}$ & $S_{D, r, N}$ & $S_{D, R, n}$ & $\begin{array}{l}S_{D, R, n} \\
\text { reinf. }\end{array}$ & $S_{D, R, N}$ \\
\hline $\begin{array}{l}\text { Value } \\
(k €)\end{array}$ & -2441.22 & -2139.95 & -2142.07 & -2150.07 & -1954.02 & -1956.14 & -1954.33 \\
\hline Benefit & 0 & $12.34 \%$ & $12.25 \%$ & $11.93 \%$ & $19.96 \%$ & $19.87 \%$ & $19.94 \%$ \\
\hline
\end{tabular}

\section{Table 17}

Summary of Objective Function values for all case studies.

\begin{tabular}{l|lllllll}
$\begin{array}{l}\text { Case } \\
\text { study }\end{array}$ & $\begin{array}{l}\mathrm{S}_{\mathrm{d}, \mathrm{r}, \mathrm{n}} \\
\text { (base) }\end{array}$ & $\mathrm{S}_{\mathrm{D}, \mathrm{r}, \mathrm{n}}$ & $\begin{array}{l}\mathrm{S}_{\mathrm{D}, \mathrm{r}, \mathrm{n}} \\
\text { reinf. }\end{array}$ & $+\mathrm{S}_{\mathrm{D}, \mathrm{r}, \mathrm{N}}$ & $\mathrm{S}_{\mathrm{D}, \mathrm{R}, \mathrm{n}}$ & $\begin{array}{l}\mathrm{S}_{\mathrm{D}, \mathrm{R}, \mathrm{n}} \\
\text { reinf. }\end{array}$ & $+\mathrm{S}_{\mathrm{D}, \mathrm{R}, \mathrm{N}}$ \\
\hline $\mathrm{A}$ & 0 & $9.44 \%$ & $9.25 \%$ & $9.16 \%$ & $17.13 \%$ & $16.94 \%$ & $17.11 \%$ \\
$\mathrm{~B}$ & 0 & $9.44 \%$ & $9.34 \%$ & $9.13 \%$ & $17.13 \%$ & $17.06 \%$ & $17.12 \%$ \\
$\mathrm{C}$ & 0 & $12.34 \%$ & $12.25 \%$ & $11.93 \%$ & $19.96 \%$ & $19.87 \%$ & $19.94 \%$
\end{tabular}


